\title{
Validity of an inertial measurement unit to assess pelvic orientation angles during gait, sit-stand transfers and step-up transfers: Comparison with an optoelectronic motion capture system
}

Citation for published version (APA):

Bolink, S. A., Naisas, H., Senden, R., Essers, H., Heyligers, I. C., Meijer, K., \& Grimm, B. (2016). Validity of an inertial measurement unit to assess pelvic orientation angles during gait, sit-stand transfers and step-up transfers: Comparison with an optoelectronic motion capture system. Medical Engineering \& Physics, 38(3), 225-231. https://doi.org/10.1016/j.medengphy.2015.11.009

Document status and date:

Published: 01/03/2016

DOI:

10.1016/j.medengphy.2015.11.009

Document Version:

Publisher's PDF, also known as Version of record

\section{Document license:}

Taverne

\section{Please check the document version of this publication:}

- A submitted manuscript is the version of the article upon submission and before peer-review. There can be important differences between the submitted version and the official published version of record. People interested in the research are advised to contact the author for the final version of the publication, or visit the DOI to the publisher's website.

- The final author version and the galley proof are versions of the publication after peer review.

- The final published version features the final layout of the paper including the volume, issue and page numbers.

Link to publication

\footnotetext{
General rights rights.

- You may freely distribute the URL identifying the publication in the public portal. please follow below link for the End User Agreement:

www.umlib.nl/taverne-license

Take down policy

If you believe that this document breaches copyright please contact us at:

repository@maastrichtuniversity.nl

providing details and we will investigate your claim.
}

Copyright and moral rights for the publications made accessible in the public portal are retained by the authors and/or other copyright owners and it is a condition of accessing publications that users recognise and abide by the legal requirements associated with these

- Users may download and print one copy of any publication from the public portal for the purpose of private study or research.

- You may not further distribute the material or use it for any profit-making activity or commercial gain

If the publication is distributed under the terms of Article 25fa of the Dutch Copyright Act, indicated by the "Taverne" license above,

Download date: 26 Apr. 2023 


\title{
Validity of an inertial measurement unit to assess pelvic orientation angles during gait, sit-stand transfers and step-up transfers: Comparison with an optoelectronic motion capture system*
}

\author{
S.A.A.N. Bolink ${ }^{\mathrm{a}, *}$, H. Naisas ${ }^{\mathrm{a}}$, R. Senden ${ }^{\mathrm{a}}$, H. Essers ${ }^{\mathrm{b}}$, I.C. Heyligers ${ }^{\mathrm{a}}$, K. Meijer ${ }^{\mathrm{b}}$, B. Grimm $^{\mathrm{a}}$ \\ a AHORSE Foundation, Atrium Medical Centre, Department of Orthopaedics Er Traumatology, Heerlen, The Netherlands \\ ${ }^{\mathrm{b}}$ Maastricht University, Department of Human Movement Science, Faculty of Health, Medicine and Life Sciences, Maastricht, The Netherlands
}

\section{A R T I C L E I N F O}

\section{Article history:}

Received 25 March 2015

Revised 18 November 2015

Accepted 29 November 2015

\section{Keywords:}

Inertial measurement unit

Optoelectronic motion capture system

Pelvic orientation angles

Gait

Sit-to-stand

Block step-up

Physical function

Performance-based test

Outcome assessment

Osteoarthritis

Arthroplasty

\begin{abstract}
A B S T R A C T
An inertial measurement unit (IMU) allows kinematic evaluation of human motion with fewer operational constraints than a gold standard optoelectronic motion capture (MOCAP) system. The study's aim was to compare IMU and MOCAP measurements of dynamic pelvic orientation angles during different activities of daily life (ADL): gait, sit-to-stand (STS) transfers and block step-up (BS) transfers. A single IMU was attached onto the lower back in seventeen healthy participants $(8 \mathrm{~F} / 9 \mathrm{M}$, age $19-31$ years; BMI $<25)$ and optical skin markers were attached onto anatomical pelvic landmarks for MOCAP measurements. Comparisons between IMU and MOCAP by Bland-Altman plots demonstrated that measurements were between 2SD of the absolute difference and Pearson's correlation coefficients were between 0.85 and 0.94 . Frontal plane pelvic angle estimations achieved a RMSE in the range of $\left[2.7^{\circ}-4.5^{\circ}\right]$ and sagittal plane measurements achieved a RMSE in the range of $\left[2.7^{\circ}-8.9^{\circ}\right]$ which were both lowest in gait. Waveform peak detection times demonstrated ICCS between 0.96 and 1.00 . These results are in accordance to other studies comparing IMU and MOCAP measurements with different applications and suggest that an IMU is a valid tool to measure dynamic pelvic angles during various activities of daily life which could be applied to monitor rehabilitation in a wide variety of musculoskeletal disorders.
\end{abstract}

(c) 2015 IPEM. Published by Elsevier Ltd. All rights reserved.

\section{Introduction}

An optoelectronic motion capture (MOCAP) system is regarded as the gold standard to quantify human body kinematics in clinical studies [1,2]. MOCAP is however not feasible for routine clinical use because it is time consuming, expensive, requires a specially equipped laboratory with trained personnel and it is limited to a specific motion capture volume, constrained by space and equipment [3-5]. Consequently, many clinical studies evaluating physical performance use timed parameters, such as the six minute walk test (6MWT), timed up-and-go test (TUG) and stair climbing test (SCT), which have limited sensitivity and may not adequately discriminate between variations in subtle pathologies [6]. An inertial measurement unit (IMU) might open new perspective for these functional tests as it allows detailed spatiotemporal and kinematic measurements of human motion in a continuous modality [7,8]. An IMU is

\footnotetext{
* Correspondence to: Department of Orthopedics, Atrium Medical Center Heerlen, Henri Dunantstraat 5, 6419 PC Heerlen, the Netherlands. Tel.: +31 655341492; fax: +31455766055.

E-mail address: stijn.bolink@mail.com, stijn009@hotmail.com (S.A.A.N. Bolink).
}

a commercially available, low-cost, small, lightweight and ambulant sensor, typically comprising a tri-axial accelerometer, tri-axial gyroscope, and tri-axial magnetometer. Through sensor fusion algorithms, the three-dimensional orientation can be estimated relative to a global coordinate system, based on the magnetic north and gravity which is referred to as Attitude and Heading Reference Systems (AHRS), traditionally expressed in Euler angles (yaw $\psi$, pitch $\theta$, and roll $\phi$ ) $[3,9]$. By attaching an IMU onto a body segment, the orientation of that body segment can be determined which allows kinematic evaluation of motion in realistic environments and conditions, with fewer operational constraints compared to MOCAP [3,10]. A systematic review of the literature by Cuesta-Vargas et al. [11] comparing IMU to gold standard optoelectronic MOCAP systems, demonstrated that an IMU can be applied to many body regions accurately and reliably but the degree of reliability is specific to the IMU system and anatomical site [11]. Most validation studies however attach the optical markers onto the IMU which means that only the measurement accuracy of the two systems is compared, but not the results of an IMU based motion analysis to an optoelectronic motion analysis [12]. Only a few studies have compared IMU with MOCAP by attaching the optical markers onto anatomical landmarks [12-15], remaining 
the variable inaccuracies due to relative motion between soft tissue and the underlying bony segments which are a potential source of measurement error [16]. Furthermore, whether the measurement error is acceptable and IMU data are considered reliable enough depends on the intended clinical application. Of interest in this paper is the routine clinical assessment of physical function in patients with hip or knee osteoarthritis (OA), for which a consensus derived set of functional tests enhanced with ambulatory motion analysis has been recommended in the literature [17]. Previous work described a method for ambulatory motion analysis of gait, sit-to-stand transfers and step-up transfers with a single inertial sensor positioned at the lower back in patients with knee OA [18] with sensitivity to postoperative changes following total knee arthroplasty [19]. This specific method has been adopted and reproduced by other researchers to assess functional outcome following total joint arthroplasty [20,21]. However, the validity of kinematic measurements from a single IMU positioned at the lower back during these activities has not yet been well determined.

The aim of this study was to compare kinematic measurements by an IMU attached on the lower back to a MOCAP system with optical markers placed on anatomical landmarks during gait, sit-stand transfers and step-up transfers, relevant for the assessment of physical function in patients with hip or knee OA [17,18].

\section{Materials and methods}

\subsection{Equipment}

Kinematic data were simultaneously obtained with an inertial measurement unit (IMU) and an optoelectronic motion capture (MOCAP) system. The IMU (size: $41 \times 63 \times 24 \mathrm{~mm}$; weight: $39 \mathrm{~g}$; MicroStrain ${ }^{\circledR}$ Inertia-Link ${ }^{\circledR}$ ) comprises a tri-axial magnetometer, triaxial gyroscope $\left( \pm 300^{\circ} / \mathrm{s}\right)$ and tri-axial accelerometer $( \pm 5 \mathrm{~g})$ [22]. The IMU's output data quantities are calibrated for misalignment and the advertised technical specifications provided by the manufacturer indicate a gyro stability bias of $\pm 0.2^{\circ} / \mathrm{s}$ for movements at an angular velocity of $\pm 300^{\circ} / \mathrm{s}$ with static accuracy of $\pm 0.5^{\circ}$ and dynamic accuracy of $\pm 2.0^{\circ}$. The IMU provides dynamic orientation angle estimation (yaw $\psi$, pitch $\theta$, and roll $\phi$ ) as separate output signals through inbuilt integration of the gyroscope signal by a microprocessor fusing the acceleration, angular rate and magnetic field vector measurements while performing fundamental data filtering to address drift error. The IMU was attached onto the skin using a double-sided adhesive tape and positioned at the lower back between both PSIS (posterior superior iliac spine) anatomical pelvic landmarks. Real-time data from the IMU were stored onto a computer via a wireless Bluetooth connection with a sampling frequency of $100 \mathrm{~Hz}$. Data analysis was performed running analysis algorithms in MATLAB ${ }^{\circledR}$ (MathWorks ${ }^{\circledR}$ ) version R2009a [18]. The MOCAP system was set-up with six VICON MX-3+ and two VICON MX-T20 cameras and one Kistler 9281A pressure plate. Emitted LED signals were reflected by skin markers with a diameter of $15 \mathrm{~mm}$ that were attached on the participants' anatomical pelvic landmarks according to the VICON's Plug In Gait Full Body Model $[23,24]$. The pressure plate was synchronized with the VICON cameras for heel strike detection during gait analysis and data were transmitted with a frequency of $200 \mathrm{~Hz}$ and analyzed with Nexus software.

\subsection{Participants}

Participants ( $n=17 ; 8$ females and 9 males; age range 1931 years; mean age 25.8 years; BMI range $18.9-24.9 \mathrm{~kg} / \mathrm{m}^{2}$; mean BMI $21.6 \mathrm{~kg} / \mathrm{m}^{2}$ ) were randomly recruited from a medical university campus. Exclusion criteria were any neurological or musculoskeletal disorder, previous lower extremity surgery, recent musculoskeletal trauma and obesity (BMI $\left.>25 \mathrm{~kg} / \mathrm{m}^{2}\right)$.

\subsection{Tasks}

Three tasks resembling activities of daily life (ADL) were used: gait, sit-to-stand transfers (STS) and block step-up transfers (BS). BS was used as a surrogate for stair climbing as it was considered a more feasible task to perform in an outpatient clinical setting. The tasks were performed in a standardized order, at self-selected speed and were all repeated twice.

(1) Gait

Participants walked a $10 \mathrm{~m}$ distance at preferred speed. Across the finish line, one last step was allowed to avoid a significant slowdown aiming to reach the marked distance [25]. The exact distance covered (10 $\mathrm{m}+$ the last step) was measured to calculate IMU-based spatiotemporal gait parameters (i.e. speed, cadence, step time) obtained from the raw antero-posterior acceleration signal which serve as a reference $[26,27]$. IMU-based kinematic measurements represent the average of multiple gait cycles from the $10 \mathrm{~m}$ walked distance whereas MOCAP-based kinematic measurements are based on one gait cycle which was identified after heel strike on the pressure plate.

(2) STS

Participants performed STS transfers at preferred speed from a height adjustable chair in a standardized position: hips and knees were flexed in a $90^{\circ}$ angle, both feet were parallel on the floor spread shoulder-width apart and arms were not allowed to swing while ascending [28].

(3) Block step-up (BS)

Participants performed BS transfers onto a $20 \mathrm{~cm}$ high wooden block at preferred speed. All participants stepped up with the right leg.

\subsection{Statistical analysis}

The output signals for dynamic pelvic angle estimations from IMU were analyzed with peak detection algorithms in MATLAB ${ }^{\circledR}$ and from MOCAP with Nexus software. The waveforms of both systems were plotted in MATLAB ${ }^{\circledR}$ to provide additional visual comparison. For each task, the range of motion (ROM) in the frontal plane and sagittal plane were calculated as these have been found the most relevant for functional assessment of gait, sit-to-stand transfers and step-up transfers with previously reported discriminative capacity between knee OA patients and healthy controls, in contrast to ROM in the transverse plane [18]. Agreements between ROM-measurements were compared by the plot of the difference between each paired measurement against the mean value of both (Bland Altman plots) and quantified by calculation of the root mean squared error (RMSE) and Pearson's correlation coefficient $(r)$. To investigate waveform peak-to-peak displacement due to filtering and integration of the IMU's gyroscope signal, waveform peak detection times between IMU and MOCAP were compared with interclass correlation coefficients (ICCs; $r$ ) [29]. For gait, time between two maxima of consecutive gait cycles was compared and for STS and BS the time between two maxima of consecutive repetitions was compared.

\section{Results}

In gait, participants walked at a mean speed of $1.27 \mathrm{~m} / \mathrm{s}$ with a step frequency of 115.6 steps/min, a mean step time of $0.52 \mathrm{~s}$ and mean step length of $0.66 \mathrm{~m}$. Measurements of the sagittal plane ROM by IMU and MOCAP demonstrated a RMSE of $2.70^{\circ}$ and a Pearson's correlation coefficient of 0.89 (Table 1 ) comparing the two measurement systems. A plot of the difference between each paired IMU and MOCAP measurement against the mean value of both (Bland-Altman) demonstrated that these differences are within two standard deviations (2SD) (Fig. 4). Comparison of frontal plane ROM measurements 
Table 1

ICC $(r)$, RMSE $\left({ }^{\circ}\right)$ and Pearson's correlation coefficient $(r)$ between IMU and MOCAP measurements in gait, STS and BS. CI $=$ confidence interval.

\begin{tabular}{|c|c|c|c|c|c|c|}
\hline & \multicolumn{3}{|l|}{ Sagittal plane } & \multicolumn{3}{|l|}{ Frontal plane } \\
\hline & $\mathrm{ICC}(r)(\mathrm{CI}, 95 \%)$ & $\operatorname{RMSE}\left({ }^{\circ}\right)$ & Pearson's $r$ & $\mathrm{ICC}(r)(\mathrm{CI}, 95 \%)$ & $\operatorname{RMSE}\left({ }^{\circ}\right)$ & Pearson's $r$ \\
\hline Gait & $0.96(0.89-0.99)$ & 2.70 & 0.94 & $1.00(0.99-1.00)$ & 2.68 & 0.91 \\
\hline STS & $0.99(0.97-1.00)$ & 8.89 & 0.92 & $1.00(0.99-1.00)$ & 4.44 & 0.89 \\
\hline BS & $0.98(0.95-0.99)$ & 6.61 & 0.86 & $0.96(0.90-0.99)$ & 3.05 & 0.85 \\
\hline
\end{tabular}


Fig. 1. Representative sample of frontal plane pelvic ROM during gait in one subjects, measured with IMU and MOCAP. Heel strikes are indicated.

between IMU and MOCAP during gait demonstrated a RMSE of $2.68^{\circ}$ and a Pearson's correlation coefficient of 0.92 (Table 1). Bland Altman plots demonstrated that these differences are within two standard deviations (2SD) (Fig. 4). A representative subject's sample waveform of the sagittal plane gait kinematics is shown in Fig. 1. The waveform's peak-to-peak detection times assessed by the two measurement systems demonstrated interclass correlation coefficients (ICC; $r$ ) of 0.96 for sagittal plane waveform peaks and 1.00 for frontal plane waveform peaks.

In STS, sagittal plane ROM measurements by IMU and MOCAP demonstrated a RMSE of $8.89^{\circ}$ and a Pearson's $r$ correlation coefficient of 0.91 (Table 1). Bland Altman plots demonstrated that these differences are within the two standard deviations (2SD) except for one outlier (Fig. 4). A random subject's sample waveform of the sagittal plane STS kinematics is shown in Fig. 2. Comparison of frontal plane ROM measurements during STS between IMU and MOCAP demonstrated a RMSE of $4.44^{\circ}$ and a Pearson's correlation coefficient of 0.89 (Table 1). Bland Altman plots demonstrated that these differences are within the two standard deviations (2SD) except for one outlier (Fig. 4). STS waveform's peak-to-peak detection times assessed by the two measurement systems demonstrated interclass correlation coefficients (ICC; $r$ ) of 0.99 for sagittal plane waveform peaks and 1.00 for frontal plane waveform peaks.

In BS, sagittal plane ROM measurements by IMU and MOCAP demonstrated a RMSE of $6.61^{\circ}$ and a Pearson's correlation coefficient of 0.87 (Table 1). Bland Altman plots demonstrated that these differences are within the two standard deviations (2SD) except for one outlier (Fig. 4). A random subject's sample waveform of the sagittal plane BS kinematics is shown in Fig. 3. Comparison of frontal plane ROM measurements during BS between IMU and MOCAP demonstrated a RMSE of $3.05^{\circ}$ and a Pearson's correlation coefficient of 0.90 (Table 1). Bland Altman plots demonstrated that these differences
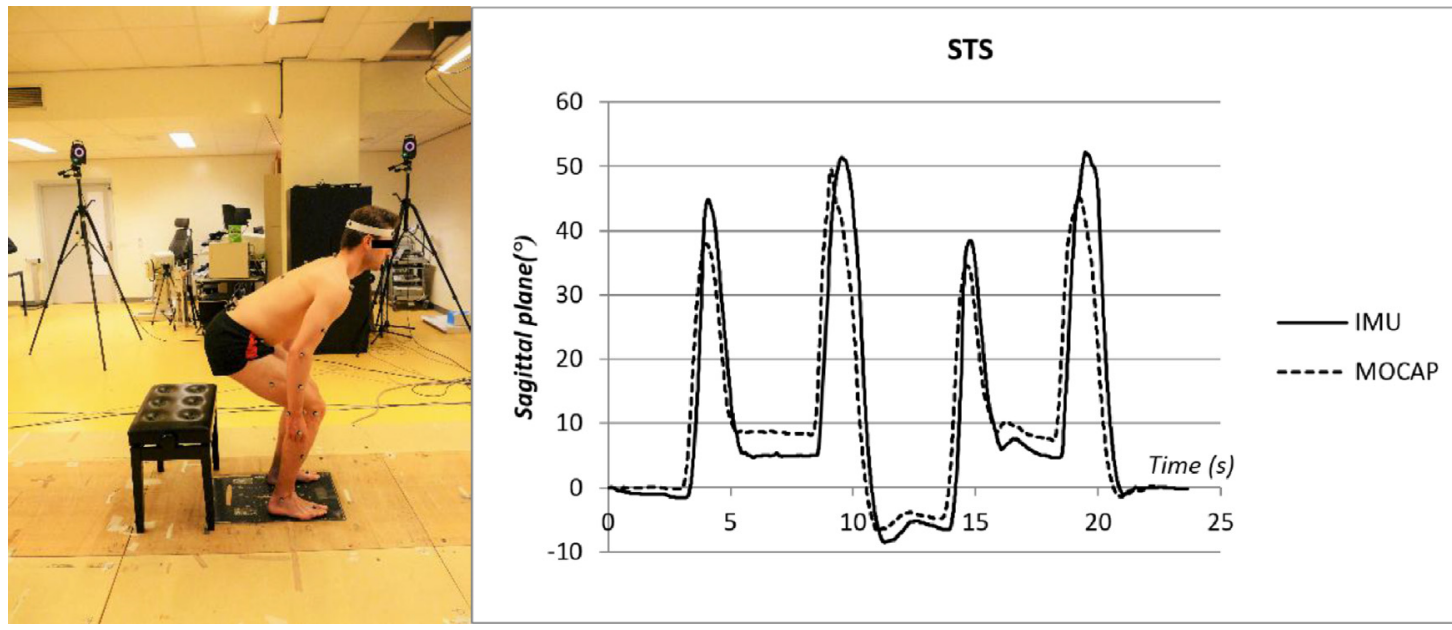

Fig. 2. Representative sample of STS sagittal plane pelvic ROM in one subject measured with IMU and MOCAP. Sit-to-stand and stand-to-sit transfers are indicated. 


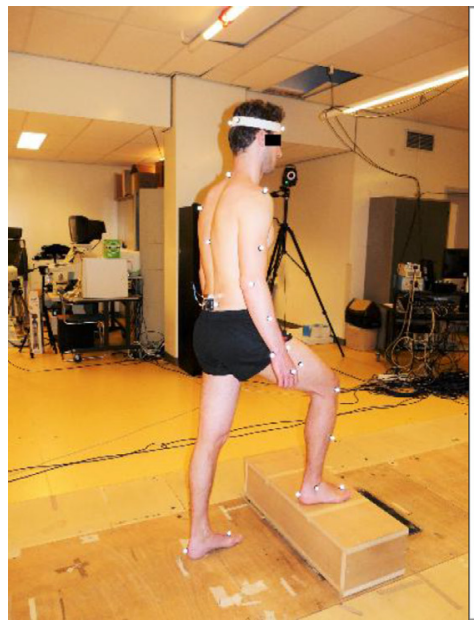

BS

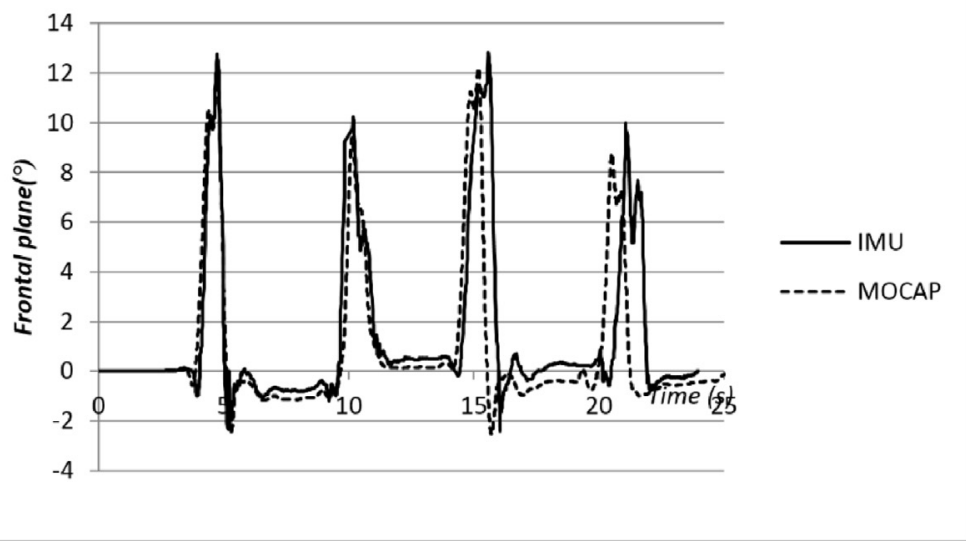

Fig. 3. Representative sample of BS frontal plane pelvic ROM in one subject measured with IMU and MOCAP. Step-up and step-down transfers are indicated.

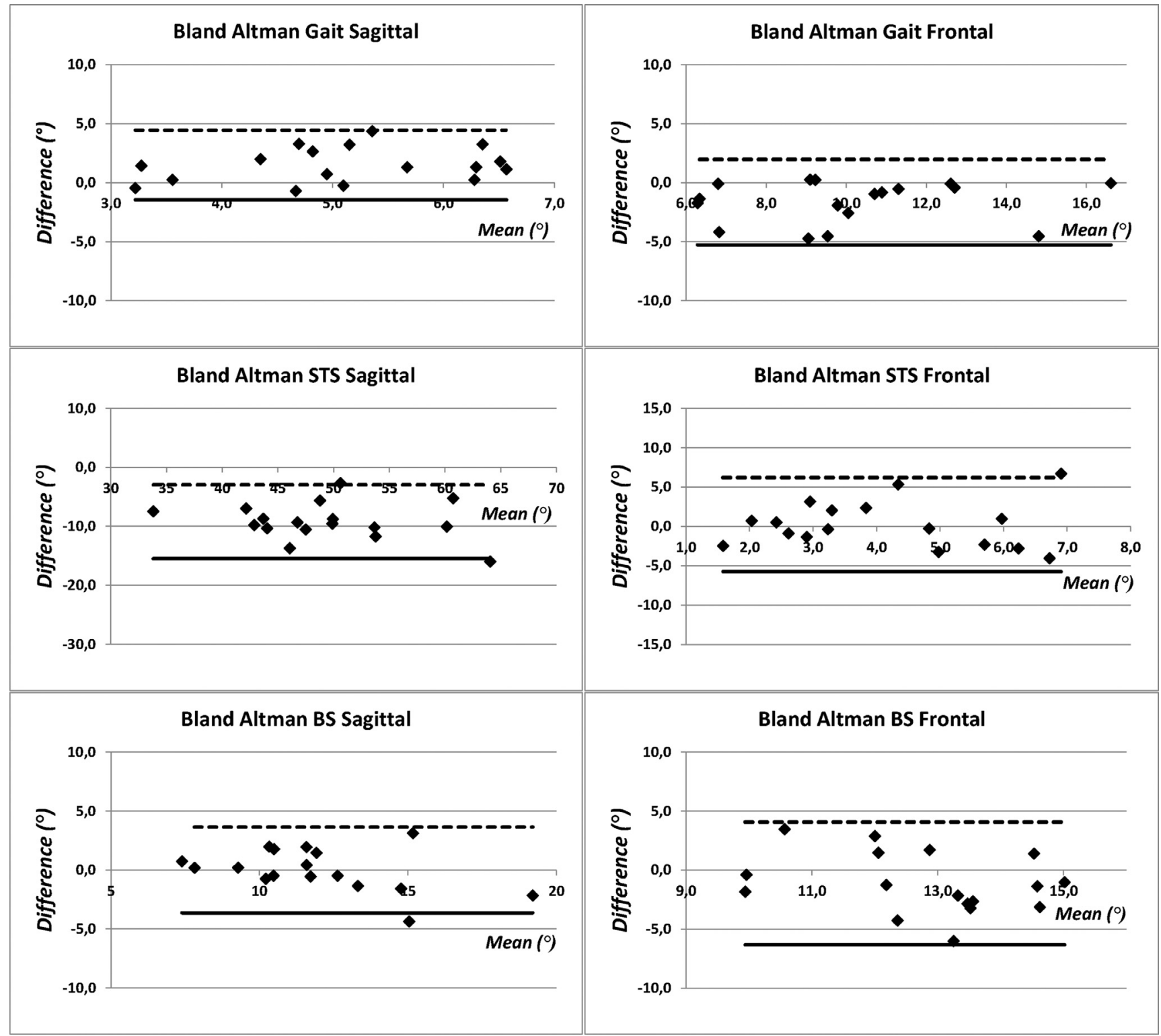

Fig. 4. Bland-Altman plots of gait, STS and BS. The solid and dashed lines represent the lower and upper limits of agreement (2 standard deviations), respectively. 
are within the two standard deviations (2SD) with no outliers (Fig. 4). BS waveform's peak-to-peak detection times assessed by the two measurement systems demonstrated interclass correlation coefficients (ICC; $r$ ) of 0.98 for sagittal plane waveform peaks and 0.96 for frontal plane waveform peaks.

\section{Discussion}

This study demonstrates that IMU based human motion analysis could provide accurate kinematic assessment of body segments compared to a MOCAP system during different activities of daily life. MOCAP is regarded as the gold standard for non-invasive human motion analysis although soft tissue and skin artifacts remain a source of potential error. For dynamic pelvic angle estimations with MOCAP, rigid plate-mounted pelvic markers have demonstrated smaller artifacts compared to body-mounted pelvic markers [30]. An IMU could be considered as a rigid plate attached onto the pelvic skin however the difference in size and weight may introduce altered soft tissue and skin artefacts compared to MOCAP, which could be an important source of measurement error between the two systems [31]. Studies that have compared IMU against MOCAP with artificial objects or with the optical markers attached onto the IMU do not account for this. Therefore, in the current study the MOCAP's optical markers were placed on anatomical pelvic landmarks, each system independently measured the pelvic range of motion, performed data analysis with system specific software and their final outcomes were compared. Reasonably good agreement of ROM-measurements between IMU and MOCAP were found as differences in measured angles were between 2SD in the Bland-Altman plots, RMSEs were between $2.68^{\circ}$ and $4.44^{\circ}$ for frontal plane pelvic angle estimation and between $2.70^{\circ}$ and $8.89^{\circ}$ for sagittal plane pelvic angle estimation and Pearson's correlation coefficients were between 0.85 and 0.94 . These results are in accordance to results from other studies comparing IMU measurements against MOCAP measurements with different applications [3,5,12,15,31-34]. Lebel et al. [3] compared three commercially available IMUs to MOCAP, attaching the IMUs and the optical markers onto an artificial object moving under laboratory conditions, and found mean absolute accuracy (ROM) below $3.1^{\circ}$ in slow motion conditions (i.e. $90^{\circ} / \mathrm{s}$ ) with significantly higher and more variable accuracy up to $7.0^{\circ}$ in fast motion conditions (i.e. $180^{\circ} / \mathrm{s}$ ). A study by Takeda et al. [31] compared hip and knee joint motion during gait assessed by IMU and MOCAP, with optical markers attached onto anatomical human body landmarks, and reported a mean RMSE of $8.72^{\circ}$ for sagittal hip joint motion (i.e. flexion/extension), a mean RMSE of $6.79^{\circ}$ for sagittal knee joint motion and a mean RMSE of $4.96^{\circ}$ for frontal hip joint motion (i.e. adduction/abduction). Seel et al. [12] compared IMU and MOCAP sagittal joint angle measurements (i.e. flexion/extension) of the knee and ankle during gait in a trans femoral amputee between the prosthesis leg and the human leg and reported RMSEs in the range of $\left[0.71^{\circ}-0.81^{\circ}\right]$ for the prosthesis leg and $\left[1.62^{\circ}-3.30^{\circ}\right]$ for the human leg, emphasizing the effect of soft tissue and skin artefacts causing measurement error. A study by van den Noort et al. [5] evaluated 3D kinematic measurements of the hip, knee and ankle joints in children with cerebral palsy (CP), with optical MOCAP markers attached onto the IMUs, and found a RMSE in the range of $\left[4.6^{\circ}-8.8^{\circ}\right]$ for sagittal plane joint motion and $\left[6.0^{\circ}-9.2^{\circ}\right]$ for frontal plane joint motion. Bauer et al. [15] investigated lumbar spine ROM and compared the angular difference between two IMUs attached at L1 and S2 against a MOCAP system, demonstrating a RMSE in the range of $\left[4.1^{\circ}-4.4^{\circ}\right]$ for sagittal plane ROM and $\left[1.8^{\circ}-1.9^{\circ}\right]$ for frontal plane ROM. Zhou et al. [33] compared elbow flexion/extension and forearm rotation by using two IMUs and reported a RMSE of $2.41^{\circ}$ and $4.83^{\circ}$ respectively. Finally, a study by Buganè et al. [14] compared the 3D pelvic kinematics during gait with a single IMU attached at the lower back to an optoelectronic MOCAP system with optical markers attached onto anatomical pelvic landmarks, and reported a RMSE smaller than $1^{\circ}$ for sagittal plane angles and smaller than $3^{\circ}$ for frontal plane angles with an average correlation coefficient $(r)$ of approximately 0.90 .

Peak detection times between IMU and MOCAP waveforms were investigated separately using interclass correlation coefficients (ICCs). As the IMU's gyroscope signal is filtered and integrated by an inbuilt microprocessor, jitter with peak-to-peak displacement is a possible result. Although the IMU signals tend to follow the same overall waveform as MOCAP, minor peak-to-peak displacement was found in the IMU signals and can be observed in the sample Figs. 13. Though, overall peak detection times for sagittal and frontal plane pelvic ROM-measurements demonstrated good agreement between the two measurement systems as ICCs were all above 0.96. A recent study by Papi et al. [35] compared MOCAP assessed timed parameters of sit-to-stand transfers (duration) and gait (stride time) with IMU assessed timed parameters, based on the antero-posterior acceleration signal, and reported comparable ICCs between 0.95 and 0.99 .

Previous work described the clinical application of IMU based motion analysis during gait, sit-to-stand transfers and step-up transfers in a cohort of patients with knee OA undergoing total knee arthroplasty, demonstrating discriminative capacity for sagittal and frontal plane ROM-measurements between pre-operative knee OA patients and healthy controls [18] and sensitivity to post-operative improvement [19]. These significant differences for ROM-measurements did not exceed the RMSE that was found for each ROM-measurement by comparing IMU to MOCAP in this study. In literature, errors up to $5^{\circ}$ are regarded as reasonable but errors that exceed $5^{\circ}$ could be considered large enough to mislead clinical interpretation [11]. Data from the studies included in the systematic review by Cuesta-Vargas et al. [11] and the previously discussed studies reporting measurement errors between IMU and MOCAP systems, revealed that in many studies measurement errors exceed $5^{\circ}$ but remain less than $10^{\circ}$. In our study results, RMSEs for frontal plane pelvic ROM-measurements during the three activities were less than $5^{\circ}$. However, the RMSE found for sagittal plane pelvic ROM-measurements during STS $\left(8.89^{\circ}\right)$ and $\mathrm{BS}\left(6.61^{\circ}\right)$ exceed the $5^{\circ}$ measurement error threshold and could be caused by the absolute ROM being bigger than the absolute ROM found for frontal plane motion, which concurs with the study results from Takeda et al. [31]. Whether our IMU data are reliable enough depends on the proposed use, with the degree of acceptable measurement variation relating directly to the intended application. The three activities that were investigated in this study have been recommended to assess physical function for patients with hip or knee osteoarthritis (OA) [17], but they are usually assessed by timing, counting or distance methods which have limited sensitivity and discriminative capacity. Enhancement with an IMU positioned at the lower back allows additional spatiotemporal measurements and kinematic measurements of the pelvis to capture compensation mechanisms for lower extremity musculoskeletal dysfunction such as decreased hip abductor muscle strength with Trendelenburg gait [36,37], excessive trunk sway to unload a painful limb during STS and BS transfers and to create momentum compensating for decreased quadriceps muscle strength $[18,38-40]$. Therefore, this method could be applied to assess physical function in a wider variety of musculoskeletal or neurological disorders, particularly in the context of rehabilitation, however it does not allow functional assessment of a single joint (e.g. hip or knee) specifically.

A few limitations of the study should be acknowledged when interpreting the results. The two systems were tested only with ablebodied participants that were relatively young (age range 19-31 years) and not obese (BMI range $18.9-24.9 \mathrm{~kg} / \mathrm{m}^{2}$ ). Soft tissue and skin artifacts may be altered in a cohort of patients with different body structures and in pathologic movement, which could potentially introduce larger measurement errors for IMU based motion analysis. Furthermore, a limitation of the proposed method is that for the assessment of compensatory trunk sway with a single IMU, the optimal sensor position has previously been defined at a position between L1 
and L2 [41]. The IMU position applied in this study would result in a slight underestimation of actual compensatory trunk sway during STS and BS transfers but because it allows accurate and reliable spatiotemporal and kinematic gait analysis [1,7,14,26,27,42,43] and for feasibility reasons, it was decided not to change the sensor position for the other two activities. Another limitation of the study is that the IMU provided orientation angles as a separate output signal, which is not measured directly but estimated by combining the acceleration, angular rate and magnetic field vector measurements. These estimations rely on the manufacturer's fusion algorithms that integrate the gyroscope signal and perform data filtering to address drifts and noise. Different filters have been proposed in literature for improving the orientation estimation by Euler angles (yaw $\psi$, pitch $\theta$, and roll $\phi$ ) $[9,44,45]$ but our specific IMU's fusion algorithms remain unknown and cause a 'black box effect'. Nonetheless, our study results demonstrate a performance equivalent to those IMUs used in previously mentioned studies [3,5,12,14,15,31-34].

\section{Conclusion}

Comparison of IMU against MOCAP based measurements of pelvic ROM in frontal and sagittal plane during activities of daily life demonstrated good agreement between the two systems. Although measurement accuracy remains subject to skin artefacts, IMU based motion analysis seems a valid tool to objectively assess ambulatory physical function and could be applied to monitor rehabilitation in a wide variety of musculoskeletal disorders, particularly in patients with hip or knee OA undergoing total joint arthroplasty.

\section{Conflict of interest}

The authors declare that there is no conflict of interest.

\section{Acknowledgments}

This research received no specific grant from any funding agency in the public, commercial, or non-profit sectors. The authors declare that this manuscript is original, has not been published before and is not currently being considered for publication elsewhere. All participants signed an informed consent and ethical approval was obtained on 27-05-2013 by the Medical Ethics Committee (METC) of the Atrium Medical Centre Heerlen, The Netherlands, with METC number: $13-\mathrm{N}-71$.

\section{References}

[1] Reininga IH, Stevens M, Wagenmakers R, Boerboom AL, Groothoff JW, Bulstra SK, Zijlstra W. Compensatory trunk movements in patients with hip osteoarthritis: accuracy and reproducibility of a body-fixed sensor-based assessment. Am J Phys Med Rehabil 2011;90(8):681-7.

[2] von Porat A, Henriksson M, Holmstrom E, Thorstensson CA, Mattsson L, Roos EM. Knee kinematics and kinetics during gait, step and hop in males with a 16 years old ACL injury compared with matched controls. Knee Surg Sports Traumatol Arthrosc 2006;14(6):546-54.

[3] Lebel K, Boissy P, Hamel M, Duval C. Inertial measures of motion for clinical biomechanics: comparative assessment of accuracy under controlled conditions - effect of velocity. PLoS One 2013;8(11):e79945.

[4] Duc C, Salvia P, Lubansu A, Feipel V, Aminian K. A wearable inertial system to assess the cervical spine mobility: comparison with an optoelectronic-based motion capture evaluation. Med Eng Phys 2014;36(1):49-56.

[5] van den Noort JC, Ferrari A, Cutti AG, Becher JG, Harlaar J. Gait analysis in children with cerebral palsy via inertial and magnetic sensors. Med Biol Eng Comput 2013;51(4):377-86

[6] Coulthard JT, Treen TT, Oates AR, Lanovaz JL. Evaluation of an inertial sensor system for analysis of timed-up-and-go under dual-task demands. Gait Posture 2015;41(4):882-7.

[7] Fong DT, Chan YY. The use of wearable inertial motion sensors in human lower limb biomechanics studies: a systematic review. Sensors (Basel) 2010;10(12):11556-65.

[8] Weiss A, Herman T, Plotnik M, Brozgol M, Maidan I, Giladi N, Gurevich T, Hausdorff JM. Can an accelerometer enhance the utility of the Timed Up \& Go Test when evaluating patients with Parkinson's disease? Med Eng Phys 2010;32(2):119-25.
[9] Renaudin V, Combettes C. Magnetic, Acceleration Fields and Gyroscope Quaternion (MAGYQ)-based attitude estimation with smartphone sensors for indoor pedestrian navigation. Sensors (Basel) 2014;14(12):22864-90.

[10] Tao W, Liu T, Zheng R, Feng H. Gait analysis using wearable sensors. Sensors (Basel) 2012;12(2):2255-83.

[11] Cuesta-Vargas AI, Galan-Mercant A, Williams JM. The use of inertial sensors system for human motion analysis. Phys Ther Rev 2010;15(6):462-73.

[12] Seel T, Raisch J, Schauer T. IMU-based joint angle measurement for gait analysis. Sensors (Basel) 2014;14(4):6891-909.

[13] Zhang JT, Novak AC, Brouwer B, Li Q. Concurrent validation of Xsens MVN measurement of lower limb joint angular kinematics. Physiol Meas 2013;34(8):N639

[14] Bugane F, Benedetti MG, D’Angeli V, Leardini A. Estimation of pelvis kinematics in level walking based on a single inertial sensor positioned close to the sacrum: validation on healthy subjects with stereophotogrammetric system. Biomed Eng Online 2014;13:146.

[15] Bauer CM, Rast FM, Ernst MJ, Kool J, Oetiker S, Rissanen SM, Suni JH, Kankaanpaa M. Concurrent validity and reliability of a novel wireless inertial measurement system to assess trunk movement. J Electromyogr Kinesiol 2015;25(5):782-90.

[16] McGinnis RS, Cain SM, Tao S, Whiteside D, Goulet GC, Gardner EC, Bedi A, Perkins NC. Accuracy of femur angles estimated by IMUs during clinical procedures used to diagnose femoroacetabular Impingement. IEEE Trans Biomed Eng 2015;62(6):1503-13.

[17] Dobson F, Hinman RS, Roos EM, Abbott JH, Stratford P, Davis AM, Buchbinder R, Snyder-Mackler L, Henrotin Y, Thumboo J, Hansen P, Bennell KL. OARSI recommended performance-based tests to assess physical function in people diagnosed with hip or knee osteoarthritis. Osteoarthr Cartil 2013;21(8):1042-52.

[18] Bolink SA, van Laarhoven SN, Lipperts M, Heyligers IC, Grimm B. Inertial sensor motion analysis of gait, sit-stand transfers and step-up transfers: differentiating knee patients from healthy controls. Physiol Meas 2012;33(11):1947-58.

[19] Bolink SA, Grimm B, Heyligers IC. Patient-reported outcome measures versus inertial performance-based outcome measures: a prospective study in patients undergoing primary total knee arthroplasty. Knee 2015:26.

[20] Hjorth MH, Stilling M, Lorenzen ND, Jakobsen SS, Soballe K, Mechlenburg I. Blockstep asymmetry 5 years after large-head metal-on-metal total hip arthroplasty is related to lower muscle mass and leg power on the implant side. Clin Biomech (Bristol, Avon) 2014;29(6):684-90.

[21] Wylde V, Lenguerrand E, Brunton L, Dieppe P, Gooberman-Hill R, Mann C, Blom AW. Does measuring the range of motion of the hip and knee add to the assessment of disability in people undergoing joint replacement? Orthop Traumatol Surg Res 2014;100(2):183-6.

[22] Gouwanda D, Gopalai AA. A robust real-time gait event detection using wireless gyroscope and its application on normal and altered gaits. Med Eng Phys 2015;37(2):219-25.

[23] Gutierrez-Farewik EM, Bartonek A, Saraste H. Comparison and evaluation of two common methods to measure center of mass displacement in three dimensions during gait. Hum Mov Sci 2006;25(2):238-56.

[24] Meldrum D, Shouldice C, Conroy R, Jones K, Forward M. Test-retest reliability of three dimensional gait analysis: including a novel approach to visualising agreement of gait cycle waveforms with Bland and Altman plots. Gait Posture 2014;39(1):265-71.

[25] Bautmans I, Jansen B, Van Keymolen B, Mets T. Reliability and clinical correlates of 3D-accelerometry based gait analysis outcomes according to age and fall-risk. Gait Posture 2011;33(3):366-72.

[26] Gonzalez RC, Lopez AM, Rodriguez-Uria J, Alvarez D, Alvarez JC. Real-time gait event detection for normal subjects from lower trunk accelerations. Gait Posture 2010;31(3):322-5.

[27] Senden R, Grimm B, Heyligers IC, Savelberg HH, Meijer K. Acceleration-based gait test for healthy subjects: reliability and reference data. Gait Posture 2009;30(2):192-6.

[28] Janssen WG, Bussmann HB, Stam HJ. Determinants of the sit-to-stand movement: a review. Phys Ther 2002;82(9):866-79.

[29] JL F. The design and analysis of clinical experiments. New York, NY: John Wiley; 1986.

[30] Vogt L, Portscher M, Brettmann K, Pfeifer K, Banzer W. Cross-validation of marker configurations to measure pelvic kinematics in gait. Gait Posture 2003;18(3):17884.

[31] Takeda R, Tadano S, Natorigawa A, Todoh M, Yoshinari S. Gait posture estimation using wearable acceleration and gyro sensors. J Biomech 2009;42(15):2486-94.

[32] Wong WY, Wong MS. Trunk posture monitoring with inertial sensors. Eur Spine J 2008;17(5):743-53.

[33] Zhou S, Fei F, Zhang G, Liu Y, Li WJ. Hand-writing motion tracking with vision-inertial sensor fusion: calibration and error correction. Sensors (Basel) 2014;14(9):15641-57.

[34] Leardini A, Lullini G, Giannini S, Berti L, Ortolani M, Caravaggi P. Validation of the angular measurements of a new inertial-measurement-unit based rehabilitation system: comparison with state-of-the-art gait analysis. J Neuroeng Rehabil 2014; $11: 136$

[35] Papi E, Osei-Kuffour D, Chen YM, McGregor AH. Use of wearable technology for performance assessment: a validation study. Med Eng Phys 2015;37(7):698704.

[36] Watelain E, Dujardin F, Babier F, Dubois D, Allard P. Pelvic and lower limb compensatory actions of subjects in an early stage of hip osteoarthritis. Arch Phys Med Rehabil 2001;82(12):1705-11. 
[37] Lenaerts G, Mulier M, Spaepen A, Van der Perre G, Jonkers I. Aberrant pelvis and hip kinematics impair hip loading before and after total hip replacement. Gait Posture 2009;30(3):296-302.

[38] Boonstra MC, Schreurs BW, Verdonschot N. The sit-to-stand movement: differences in performance between patients after primary total hip arthroplasty and revision total hip arthroplasty with acetabular bone impaction grafting. Phys Ther 2011;91(4):547-54.

[39] Boonstra MC, Schwering PJ, De Waal Malefijt MC, Verdonschot N. Sit-to-stand movement as a performance-based measure for patients with total knee arthroplasty. Phys Ther 2010;90(2):149-56.

[40] Soangra R, Lockhart TE. A comparative study for performance evaluation of sit-tostand task with body worn sensor and existing laboratory methods. Biomed Sci Instrum 2012;48:407-14.
[41] Faber GS, Kingma I, Bruijn SM, van Dieen JH. Optimal inertial sensor location for ambulatory measurement of trunk inclination. J Biomech 2009;42(14):2406-9.

[42] Senden R, Grimm B, Meijer K, Savelberg H. Heyligers IC. The importance to including objective functional outcomes in the clinical follow up of total knee arthroplasty patients. Knee 2011;18(5):306-11.

[43] Zijlstra W, Hof AL. Assessment of spatio-temporal gait parameters from trunk accelerations during human walking. Gait Posture 2003;18(2):1-10.

[44] Guerrero-Castellanos JF, Madrigal-Sastre H, Durand S, Torres L, MunozHernandez GA. A robust nonlinear observer for real-time attitude estimation using low-cost MEMS inertial sensors. Sensors (Basel) 2013;13(11):15138-58.

[45] Janota A, Simak V, Nemec D, Hrbcek J. Improving the precision and speed of Euler angles computation from low-cost rotation sensor data. Sensors (Basel) 2015;15(3):7016-39. 